\title{
A Digital Radiographic Study for Gender Prediction Using Mandibular Indices
}

\author{
Dr. Shiva Kumar B, Dr. Deepthi.B C.
}

\begin{abstract}
Human identification is the goal of forensic dentistry and dental records,importantly the radiographic images like the orthopantomographs and intra oral radiographs form the basis to identify people. In this paper we attempt to set forth the foundations of a biometric system to compare and evaluate various measurements of mandibular ramus, mental index and their relationship to sex and also the usefulness of these parameters in sex determination. The Radiographs were taken by Kodak 8000C Digital Panoramic and Cephalometric System (73 kVp, $12 \mathrm{~mA}, 13.9 \mathrm{~s})$ and mandibular ramus measurements carried out using 3.0 software.Initial experimental results on a small database of radiographs indicate that matching dental images based on mandibular ramus and mental indices and their relative positions is a feasible method for forensic analysis of human gender.
\end{abstract}

Keywords: Forensic odontology, mandiblular ramus, mental index, sex determination, radiographs.

\section{Introduction}

Forensic odontology is an investigative aspect of dentistry that analyzes dental evidence for human identification. Apart from assisting in the identification of an individual, it reveals the age and gender of the same. Determination of sex using skeletal remains presents a great problem for forensic experts especially when only fragments of the body are recovered. ${ }^{1}$

The identification of human skeletal remains is considered an initial step in forensic investigations and is crucial for further analysis. ${ }^{2}$ In the adult skeleton, sex determination is usually first step of the identification process asubsequent methods for age and stature estimation are sex dependent. The reliability of sex determination depends on the completeness of the remains and the degree of sexual dimorphism inherent in the population. ${ }^{3}$ When the entire adult skeleton is available for analysis, sex can be determined up to $100 \%$ accuracy, but in cases of mass disasters where usually fragmented bones are found, sex determination with $100 \%$ accuracy is not possible and it depends largely on the available parts of skeleton. ${ }^{2,3}$ Chronological age assessment is an important part of medico-legal practice. The procedures for age determination are complex and involve the consideration of many factors. Changes related to chronological age are seen in both hard and soft tissue 4.5 among dental hard tissues and bone are extremely resistant to fire and are usually the only remains after an extended period of burial.

The relative development (size, strength, and angulation) of the muscles of mastication is known to influence the expression of mandibular dimorphism as masticatory forces exerted are different for males and females. ${ }^{6}$ Humphrey et al showed that the sites associated with the greatest morphological changes in size and remodeling during growth, mandibular condyle, and ramus in particular are generally the most sexually dimorphic. Measurements of the mandibular ramus tend to show higher sexual dimorphism, and differences between the sexes are generally more marked in the mandibular ramus than in the mandibular body. ${ }^{7} \mathrm{~A}$ number of methods for age determination have been proposed. These can be classified in four categories including clinical, histological, chemical and radiological analysis. In the living persons, any or all of the above methods can be used to determine age, in cases where actual age is not known or is to be confirmed. However, in case of a dead person, postmortem changes such as decomposition, mutilation or skeletonization may make identification progressively more difficult almost to the point of impossibility. ${ }^{8}$ Dry skull's orthopantomography (OPG) are frequently used on scientific research or forensic investigations. Dental methods are considered to be a reliable tool when other identification methods fail. ${ }^{9}$

Dentofacial radiography has become a routine procedure in the dental, medical, and hospital clinics. The radiographs are taken at different periods during the lifetime of large segments of the population. ${ }^{10}$.In forensic anthropology, comparison of ante mortem and postmortem radiographs is one of the cornerstones of positive identification of human remains. Ante mortem orthopantomograms may be of great value in the identification of human remains. ${ }^{11}$

This paper aims to evaluate the usefulness of mandibular indices in sex and age estimation in Bangalore population and propose the use of same in forensic analysis. The present study was designed with the following aims and objectives:

1) To measure, compare, and evaluate the various measurements of mandibular ramus and its relationship to sex of the patient.

2) To measure compare and evaluate the mental index and its relationship to sex of the patient.

3) To assess the usefulness of mandibular ramus and mental index as an aid in sex determination

Materials and Method :A retrospective study was conducted using orthopantomographs of 60males and 60females of Bangalore population in the age group between 20 and 60 years. Ideal orthopantomographs of completely dentate patients with right head alignment, contrast and clear visible mandibular borders, condyle ,ramus and mental foramen were selected for the study. Age sex and dental status of the patient were recorded. ${ }^{12}$ Pathological, fractured, developmental disturbances of the mandible, deformed and completely edentulous mandibles were excluded from the study. ${ }^{13}$ Radiographs taken by Kodak 8000C Digital Panoramic and Cephalometric System (73 kVp, 12 mA, 13.9 


\section{International Journal of Science and Research (IJSR) \\ ISSN (Online): 2319-7064}

Index Copernicus Value (2013): 6.14 | Impact Factor (2015): 6.391

s) were used for the study.. Mandibular ramus and mental index measurements were carried out using Master View 3.0 software. The radiographs were grouped into three 10 year age groups ; Group 1 : 21-30, Group 2: 31-40, Group 3 :41-50 Group 4: 51-60 with 15 subjects in each group. The mandibular ramus measurments and the mental indices were recorded by moving the mouse to join lines within the chosen anatomical points on the OPG (mouse driven method), the measurements recorded were :

1) Maximum ramus breadth: The distance between the mostanterior point on the mandibular ramus and a line connecting the most posterior point on the condyle and the angle of jaw. ${ }^{[1,7]}$

2) Minimum ramus breadth:Smallest anterior-posterior diameter of the ramus. ${ }^{[1]}$

3) Maximum ramus height: Height of theramus of the mandible from the most superior point on the mandibular condyle to the tubercle, or most protruding portion of the inferior border of the ramus. ${ }^{[1]}$

4) Coronoid height: Projective distance between coronion and lower wall of the bone. ${ }^{[1]}$

5) Mental index : mandibular cortical width between the mental foramen.

\section{Statistical analysis and Results}

SPSS 13.0 Discriminant function analysis was used to statistically analyze the data and to determine variables to differentiate and predict the gender through the skeletal measurements.Descriptive statistics of five mandibular ramus measurements and associated univariate $F$ ratios for both sexes are shown in Table 1 . We noticed that each variable was a significant predictor in classifying a given sample $(P<0.001)$. The mean values showed that all dimensions were higher for males compared to females. Mean measurements between males and females are shown in Figure 3. The F-statistic values indicated that mandibular measurements expressing the greatest sexual dimorphism were minimum ramus breadth followed by condylar height and projective height of ramus.

Table 1: group 1(21 -30)

\begin{tabular}{|c|c|c|c|c|c|c|}
\hline \multirow{2}{*}{ Variable } & \multicolumn{2}{|c|}{ Male } & \multicolumn{2}{|c|}{ Female } & Wilk's & P value \\
\cline { 2 - 6 } & \multicolumn{2}{|c|}{ Mean SD } & \multicolumn{2}{|c|}{$\begin{array}{c}\text { Mean } \\
\text { SD }\end{array}$} & & \\
\hline $\begin{array}{c}\text { Maximum } \\
\text { ramus width }\end{array}$ & 72.40 & \pm 5.46 & 67.65 & \pm 5.03 & 0.789 & $<0.001$ \\
\hline $\begin{array}{c}\text { Minimum } \\
\text { ramus width }\end{array}$ & 49.50 & \pm 4.66 & 40.89 & \pm 4.12 & 0.798 & $<0.001$ \\
\hline $\begin{array}{c}\text { Maximum } \\
\text { ramus height }\end{array}$ & 128.95 & \pm 8.21 & 113.97 & \pm 6.90 & 0.823 & $<0.001$ \\
\hline $\begin{array}{c}\text { Coronoid } \\
\text { height }\end{array}$ & 115.72 & \pm 10.31 & 102.54 & \pm 7.40 & 0.827 & $<0.001$ \\
\hline Mental index & 12.65 & \pm 2.29 & 9.43 & \pm 1.98 & 0.867 & $<0.001$ \\
\hline
\end{tabular}

Table 2: Linear discriminant function:

\begin{tabular}{|l|l|l|}
\hline Variable & Male & Female \\
\hline Constant & -179.56 & -160.65 \\
\hline Maximum ramus width & 1.475 & 1.139 \\
\hline Minimum ramus width & 1.452 & 0.896 \\
\hline Maximum ramus height & 2.345 & 2.108 \\
\hline Coronoid height & 0.0798 & 0.0569 \\
\hline Mental index & 0.0231 & 0.0140 \\
\hline
\end{tabular}

Table 3: Group 2(31 -40)

\begin{tabular}{|c|c|c|c|c|c|c|}
\hline \multirow{2}{*}{ Variable } & \multicolumn{2}{|c|}{ Male } & \multicolumn{2}{c|}{ Female } & Wilk's & $\begin{array}{c}\text { P } \\
\text { value }\end{array}$ \\
\cline { 2 - 7 } & Mean & SD & \multicolumn{1}{|c|}{ Mean } & SD & & $<0.001$ \\
\hline $\begin{array}{c}\text { Maximum } \\
\text { ramus width }\end{array}$ & 69.85 & \pm 5.34 & 65.98 & \pm 5.80 & 0.804 & $<0.001$ \\
\hline $\begin{array}{c}\text { Minimum } \\
\text { ramus width }\end{array}$ & 37.70 & \pm 4.78 & 35.47 & \pm 4.65 & 0.818 & $<0.001$ \\
\hline $\begin{array}{c}\text { Maximum } \\
\text { ramus height }\end{array}$ & 126.85 & \pm 8.90 & 106.56 & \pm 6.03 & 0.845 & $<0.001$ \\
\hline $\begin{array}{c}\text { Coronoid } \\
\text { height }\end{array}$ & 109.92 & \pm 09.36 & 104.05 & \pm 7.41 & 0.764 & $<0.001$ \\
\hline Mental index & 10.65 & \pm 2.21 & 8.78 & \pm 2.08 & 0.814 & $<0.001$ \\
\hline
\end{tabular}

Table 4: group 3(41-50)

\begin{tabular}{|c|c|c|c|c|c|c|}
\hline \multirow[t]{2}{*}{ Variable } & \multicolumn{2}{|r|}{ Male } & \multicolumn{2}{|c|}{ Female } & \multirow[t]{2}{*}{ Wilk's } & \multirow{2}{*}{$\begin{array}{c}\mathrm{P} \\
\text { value }\end{array}$} \\
\hline & Mean & SD & Mean & SD & & \\
\hline $\begin{array}{l}\text { Maximum } \\
\text { ramus width }\end{array}$ & 60.54 & \pm 4.68 & 56.98 & \pm 4.87 & 0.854 & $<0.001$ \\
\hline $\begin{array}{l}\text { Minimum } \\
\text { ramus width }\end{array}$ & 35.98 & \pm 4.56 & 33.69 & \pm 4.43 & 0.708 & $<0.001$ \\
\hline $\begin{array}{l}\text { Maximum } \\
\text { ramus height }\end{array}$ & 127.5 & \pm 9.56 & 102.68 & \pm 5.91 & 0.841 & $<0.001$ \\
\hline $\begin{array}{c}\text { Coronoid } \\
\text { height }\end{array}$ & 110.67 & \pm 09.90 & 101.40 & \pm 8.43 & 0.785 & $<0.001$ \\
\hline Mental index & 09.56 & \pm 1.97 & 7.99 & \pm 2.00 & 0.832 & $\begin{array}{l}<0.001 \\
\end{array}$ \\
\hline
\end{tabular}

Table 5: group 3(51-60)

\begin{tabular}{|c|c|c|c|c|c|c|}
\hline \multirow{2}{*}{ Variable } & \multicolumn{2}{|c|}{ Male } & \multicolumn{2}{|c|}{ Female } & Wilk's & $\begin{array}{c}\text { P } \\
\text { value }\end{array}$ \\
\cline { 2 - 7 } & Mean SD & \multicolumn{2}{|c|}{ Mean SD } & Sn \\
\hline $\begin{array}{c}\text { Maximum } \\
\text { ramus width }\end{array}$ & 56.27 & \pm 5.63 & 50.50 & \pm 4.24 & 0.769 & $<0.001$ \\
\hline $\begin{array}{c}\text { Minimum } \\
\text { ramus width }\end{array}$ & 33.65 & \pm 4.98 & 30.81 & $\pm 5,89$ & 0.802 & $<0.001$ \\
\hline $\begin{array}{c}\text { Maximum } \\
\text { ramus height }\end{array}$ & 118.59 & \pm 8.90 & 118.09 & \pm 5.50 & 0.818 & $<0.001$ \\
\hline $\begin{array}{c}\text { Coronoid } \\
\text { height }\end{array}$ & 106.67 & \pm 10.65 & 101.40 & \pm 7.93 & 0.842 & $<0.001$ \\
\hline Mental index & 07.56 & \pm 1.54 & 07.43 & \pm 1.97 & 0.730 & $<0.001$ \\
\hline
\end{tabular}

\section{Discussion}

The identification of sex from human remains is of fundamental importance in forensic medicine and anthropology, especially in criminal investigations as well as in the identification of missing persons and in attempts at reconstructing the lives of ancient populations. One of the important aspects of forensics is to determine sex from fragmented jaws and dentition. ${ }^{14}$ Identification of sex based on morphological marks is subjective and likely to be inaccurate, but methods based on measurements and morphometry are accurate and can be used in determination of sex from the skull. ${ }^{15,16}$ Mandibles were used for the analysis for two simple reasons: firstly, there appears to be a paucity of standards utilizing this element and secondly, this bone is often recovered largely intact.

The accuracy of panoramic radiography in providing anatomic measurements has been established. Orthopantomograph has been advocated routinely and widely used by the clinicians as an appropriate screening tool for the diagnosis of oral diseases. The principal advantages of panoramic images are their broad coverage, low patient radiation dose, and the short time required for image acquisition. ${ }^{19}$ Other advantages are that interference of superimposed images are not encountered. Also the contrast 


\section{International Journal of Science and Research (IJSR) \\ ISSN (Online): 2319-7064 \\ Index Copernicus Value (2013): 6.14 | Impact Factor (2015): 6.391}

and brightness enhancement and enlargement of images provide an accurate and reproducible method of measuring the chosen points. ${ }^{18}$ The limitations of this technique are magnification and geometric distortion, the vertical dimension in contrast to the horizontal dimension is little altered, and this technique is quite sensitive to positioning errors because of relatively narrow image layer. ${ }^{19}$ However, in our study, this limitation did not affect our results since all images were uniformly magnified.Kambylafkaset al.concluded that the use of the panoramic radiograph for evaluation of total ramal height is reliable and an asymmetry of more than $6 \%$ is an indication of a true asymmetry ${ }^{20}$. Schulze et al. found that the most reliable measurements were obtained for linear objects in the horizontal plane and digital measurements are sufficiently accurate for clinical use. $^{21}$

In this study, Discriminant function analysis was used to study the mandibular ramus measurements Each of the five variables measured on mandibular ramus using orthopantomograph showed statistically significant sex differences between sexes, indicating that ramus expresses strong sexual dimorphism. The mandibular ramus demonstrated greatest univariate sexual dimorphism in terms of minimum ramus breadth, condylar height, followed by projective height of ramus. Overall prediction rate using all five variables was $76 \%$ and the accuracy can be increased by repeated iterations. Humphreyet al. ${ }^{7}$ emphasized that almost any site of mandibular bone deposition, or resorption, or remodeling for that matter, seems to have a potential for becoming sexually dimorphic. Hence, mandibular condyle and ramus in particular are generally the most sexually dimorphic as they are the sites associated with the greatest morphological changes in size and remodeling during growth. ${ }^{26}$

Giles measured mandibles of known sex using anthropometric measurements and reported mandibular ramus height, maximum ramus breadth, and minimum ramus breadth as highly significant, with an accuracy of $85 \%$ in American Whites and Negroes. ${ }^{22}$ Steyn and Iscan (1998) achieved an accuracy of $81.5 \%$ with five mandibular parameters (i.e. bigonial breadth, total mandibular length, bicondylar breadth, minimum ramus breadth, and goniongnathion) in South African Whites, which is comparable with the present study results. ${ }^{23}$ Saini et al. conducted a study on dry adult mandibles of northern part of India and found that ramus expresses strong sexual dimorphism in this population. The overall prediction rate using five variables was $80.2 \%$. The best parameters were coronoid height, condylar height, and projective height of ramus, and breadth measurements were not very dimorphic in their sample. ${ }^{2}$

Minimum ramus breadth measurement was found to be the best parameter in the present study, which is consistent with other osteometric studies by Giles (1964) and Vodanovic (2006), where breadth measurements were found to be very dimorphic. This is related to the differences in musculoskeletal development and to the differences related to a different growth trajectory in males and females. Limitations of this study are the inability to reliably assign sex in the sub-adult range and inability to assess the gender in case of edentulous patients. ${ }^{22}$ It has been established that socio-environmental factors (e.g. nutrition, food, climate, pathologies, etc.) influence the development, and thus the appearance of bones. Numerous studies have demonstrated that skeletal characteristics differ in each population and have emphasized the need for population-specific osteometric standards for sex determination. ${ }^{24,25}$

Conclusion :

The present study which has been conducted to evaluate various mandibular indices in digital panoramic radiograph to identify possible interrelationships between indices and sex of the patient analysed the results concluded that coronoid height and the mental index can be used effectively in identification of sex. Whereas maximum and minimum breadth of ramus of the mandible can be used for sex determination only in older age group and for the age determination can be used only for females. Considering the small sample size used in this present study, the study with large proportion of samples may be necessary to confirm the results of our study conclusively.

\section{References}

[1] Sopher I.M. Forensic Dentistry , Charles Thompson Co.1976;156

[2] Saini V, Srivastava R, Rai RK, Shamal SN, Singh TB, Tripathi SK. Mandibular ramus: An indicator for sex in fragmentary mandible. J Forensic Sci 2011;56(Suppl1):S13-6.

[3] Scheuer L. Application of osteology to forensic medicine. ClinAnat2002;15:297-312.

[4] Mohite DP, Chaudhary MS, Mohite PM, Patil SP. Age assessment from mandible: Comparison of radiographic and histologic methods. Rom J MorpholEmbryol. 2011;52:659-68. [PubMed]

[5] Prabhu SR, Wilson DF, Daftary DK, Johnson NW. Oral Diseases in the Tropics. Oxford: Oxford University Press; 1993. pp. 758-9.

[6] Franklin D, O'Higgins P, Oxnard CE, Dadour I. Discriminant function sexing of the mandible of Indigenous South Africans. Forensic Sci Int. 2008; 179:84.e1-5.

[7] Humphrey LT, Dean MC, Stringer CB. Morphological variation in great ape and modern human mandibles. J Anat. 1999;195:491-513.

[8] Durić M, Rakocević Z, Donić D. The Reliability of sex determination of skeletons from forensic context in the Balkans. Forensic Sci Int. 2005;147:159-64.

[9] Maat GJ, Maes A, Aarents MJ, Nagelkerke NJ. Histological age prediction from the femur in a contemporary Dutch sample. The decrease of nonremodeled bone in the anterior cortex. J Forensic Sci. 2006;51:230-7. [PubMed]

[10] Sassouni V. Dentofacial radiography in forensic dentistry. J dent Res Jan./Feb. Supplement. 1963;42(1):274-302.

[11] Kahana T, Hiss J. Forensic radiology. Br J Radiol. 1999;72:129-33.

[12] Annamalaiponnuswamy Indira, Archana Markande, Maria P David Mandibular Ramus: An indicator for sex determination - A Digital radiographic Study. Journal of Forensic Dental Sciences/ july-december 2012/vol 4/ issue 2. 


\section{International Journal of Science and Research (IJSR) \\ ISSN (Online): 2319-7064}

Index Copernicus Value (2013): 6.14 | Impact Factor (2015): 6.391

[13] V. Poongodi, R. Kanmani, M. S. Anandi et al, Prediction of age and gender using digital radiographic method: A retrospective study.

[14] Vodanovic M, Dumancic J, Demo Z, Mihelic D. Determination of sex by discriminant function analysis of mandibles from two Croatian archaeological sites. ActaStomatol Croat. 2006;40:263-77.

[15] Humphrey LT, Dean MC, Stringer CB. Morphological variation in great ape and modern human mandibles. J Anat. 1999;195:491-513.

[16] Franklin D, O'Higgins P, Oxnard CE, Dadour I. Discriminant function sexing of the mandible of Indigenous South Africans. Forensic Sci Int. 2008;179:84.e1-5.

[17] Franklin D, Oxnard CE, O'Higgins P, Dadour I. Sexual dimorphism in the subadult mandible: Quantification using geometric morphometrics. J Forensic Sci. 2007;52:6-10.

[18] Shahabi M, Ramazanzadeh BA, Mokhber N. Comparison between the external gonial angle in panoramic radiographs and lateral cephalograms of adult patients with Class I malocclusion. J Oral Sci. 2009;51:425-9.

[19] Razi T, Moslemzade SH, Razi S. Comparison of linear dimensions and angular measurements on panoramic images taken with two machines. Journal of Dental Research, Dental Clinics, Dental Prospects. 2009;3:710.

[20] Kambylafkas P, Murdock E, Gilda E, Tallents RH, Kyrkanides S. Validity of panoramic

[21] Schulze R, Krummenauer F, Schalldac F, d'Hooedt B Precision and accuracy of measurements in digital panoramic radiography. DentomaxillofacRadiol. 2000;29:52-6.

[22] Giles E. Sex determination by discriminant function analysis of the mandible. Am $\mathrm{J}$ PhysAnthropol. 1964;22:129-35.

[23] Steyn M, Iscan MY. Sexual dimorphism in the crania and mandibles of South African whites. Forensic Sci Int. 1998;98:9-16.

[24] Hu KS, Koh KS, Han SH, Shin KJ, Kim HJ. Sex determination using nonmetric characteristics of the mandible in Koreans. J Forensic Sci. 2006;51:1376-82.

[25] Laster WS, Ludlow JB, Bailey LJ, Hershey HG. Accuracy of measurements of mandibular anatomy and prediction of asymmetry in panoramic radiographic images. DentomaxillofacRadiol. 2005;34:343-9.

[26] Oettlé AC, Pretorius E, Steyn M. Geometric Morphometric Analysis of Mandibular Ramus Flexure. Am J PhysAnthropol. 2005;128:623-9.

\section{Author Profile}

Dr, Shiva Kumar.B. is Senior lecturer, Department of conservative dentistry \& endodontics, D.A.P.M.R.V.Dental college, CA 37,24 $4^{\text {th }}$ main ,J.P.Nagar, $1^{\text {st }}$ phase, Bangalore- 560078.

Dr. Deepthi. B. C, Consultant Prosthodontist \&Implantologist, Vasan Dental Care,Rajajinagar, Bangalore.- 560010. 